\title{
Selective Ligation of Uterine Artery Branches Accelerates Fetal Growth in the Rat
}

\author{
EDWARD S. OGATA AND SANDRA L. FINLEY
}

Departments of Pediatrics, Obstetrics and Gynecology, Northwestern University Medical School, Prentice

Women's Hospital of Northwestern Memorial Hospital and Children's Memorial Hospital, Chicago, Illinois

\begin{abstract}
We determined if reducing litter number by selective fetal ablation (A) might enhance the growth of the surviving fetuses. On day 14 of the rat's 21.5-day gestation, we ligated branches of the uterine artery at their secondary division. Each of these branches supplies a placenta and its fetus, and ligation kills them. Every other fetus in litters of eight to 14 fetuses was ablated. Each A maternal rat was matched to a control with an equal number of fetuses. Ablation reduced fetal number (from 8-14 to 47) and increased fetal growth (birth weight $5.84 \pm 0.05$ versus $5.20 \pm 0.05 \mathrm{~g}, p<0.001$ ). In the $A$ but not control litters, newborn body mass was negatively related to litter number. Fetuses of A litters had increased carcass, liver, and brain mass. On days 18 and 19, fetal plasma glucose concentrations, fetal/maternal glucose ratios, insulin concentrations, and hepatic glycogen concentrations were increased suggesting that $\mathbf{A}$ increases glucose provision to the surviving fetuses. Although these observations imply that $\mathbf{A}$ enhances glucose provision resulting in stimulated growth of insulin-sensitive tissues, the growth of the brain, purportedly a tissue not sensitive to insulin, was also increased. In addition, the growth rate of $A$ fetuses continued to be increased on days 20 and 21 despite normal fetal plasma glucose and insulin. These observations indicate that with $A$, factors other than insulin also stimulated growth. Of note, newborn A pups developed hypoglycemia at 20 and $60 \mathrm{~min}$ as a result of increased insulin secretion. Newborn A pups also failed to increase hepatic cytosolic phosphoenolpyruvate carboxykinase. Selective uterine artery ligation is reproducible, relatively easy to implement, and may prove to be useful for studying the phenomenon of accelerated fetal growth. (Pediatr Res 24: 384-390, 1988)
\end{abstract}

\section{Abbreviations}

A, ablation

PEPCK, phosphoenolpyruvate carboxykinase

The determinants of fetal growth are numerous and not completely delineated. Glucose and amino acid availability and fetal insulin secretion are important to stimulate and sustain fetal growth $(1,2)$. Less is known about the effects of physical factors such as litter number and uteroplacental blood flow, and few animal models are available to assess the effects of these variables on intrauterine growth. In normal litters of polytococcous animals, the number of fetuses in a litter is roughly inversely related

Received April 11, 1988; accepted May 24, 1988.

Correspondence Edward S. Ogata, M.D., Division of Neonatology, Prentice Women's Hospital, 333 East Superior, Suite 1106, Chicago, IL 60611.

Supported in part by NIH 1 PO 119070 and the Juvenile Diabetes Foundation. to birth weight $(3,4)$. Whereas reducing litter number by such means as aspiration (5) or electrocautery (6) may enhance the growth of the remaining fetuses, these techniques have not been assessed in a systematic manner.

In the human, being excessively large at birth greatly increases the risk of birth trauma (7) and is associated with such morbidities as hypoglycemia (8). To better understand the mechanisms responsible for fetal growth, a reproducible method for accelerating intrauterine growth would be desirable. We have devised a method to accelerate intrauterine growth in the rat that involves ligation of the secondary uterine arteries during late gestation. This kills the fetuses supplied by these vessels and enhances the growth of the remaining fetuses. Although the mechanisms for stimulating intrauterine growth are not absolutely clear, the accelerated growth of fetuses is to some extent related to enhanced glucose availability with consequent stimulation of fetal insulin secretion.

\section{MATERIALS AND METHODS}

Surgery. We used pregnant Sprague-Dawley rats who had a prepregnancy weight of 170-190 g (Harlan Laboratories, Madison, WI). Gestation was timed to within $6 \mathrm{~h}$ of mating. On day 14 of their 21.5-day gestation, we anesthetized the rats with intraperitoneal chloral hydrate $(35 \mathrm{mg} / 100 \mathrm{~g}$ body weight) and with aseptic technique exposed each horn of the uterus with special attention to the branches of the uterine artery. In the rat, the uterine artery is a loop fed at the top from the abdominal aorta on the right and renal artery on the left and at the bottom from the iliac arteries. Figure 1 details the distribution of an uterine artery. The arteries originating from the main artery undergo several generations of branching. An artery after the second branching leads directly to the region of the uterus overlying the placenta of a fetus and serves as their blood source. We ligated the arterial branch at this point with 4-0 silk suture. Arteries to every other fetus in both uterine horns were ligated in this manner. In successive rats we alternated the ligation sequence by beginning with either the arteries to the uppermost or the second highest fetuses in a horn. We used only rats with eight to 14 fetuses. For controls, we matched each rat undergoing ligation to a rat with an equivalent number of fetuses. The uterine horns of the control rats were exposed and manipulated to the same extent as the experimental animals but no ligation was performed. We closed the abdominal musculature with 4-0 chromic suture and the skin with wound clips. The entire procedure required 10-15 min and rats were awake within $1 \mathrm{~h}$ of initiation of anesthesia. Before and after surgery, maternal rats had ad libitum access to food (Purina Rat Chow, Purina, St. Louis, MO) and water. In other experiments, we used the same ligation method in rats at other points (days $11-13$ and 15-20) in gestation. In three other groups of mothers on day 14 we ligated arteries to 1) all but one fetus, 2) two to three fetuses/ entire litter, or 3) a single fetus/entire litter. Control rats were subjected to sham ligation in each of these experiments. 


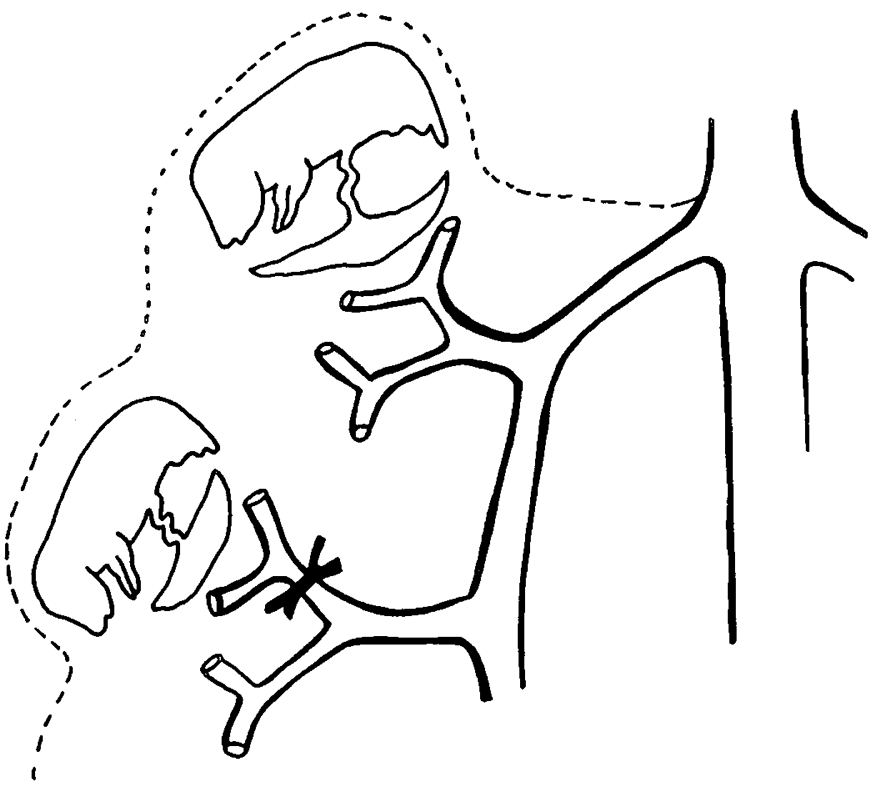

Fig. 1. Schematic diagram of the upper area of a horn of the bicornuate uterus of the rat. The secondary branches of the uterine artery go directly to the area of uterine wall over the placenta of a fetus. We ligated these arteries for every other fetus in each uterine horns.

Fetal sampling. On days 18 to 21 , we used the method of Girard et al. (9) to obtain blood from each fetus with the fetalplacental circulation intact. We could not collect individual fetal blood samples in sufficient quantity for analysis before day 18 . The mother was anesthetized with pentobarbitol $(5 \mathrm{mg} / 100 \mathrm{~g}$ body weight) and the uterus exposed and sequentially incised so that individual fetuses could be carefully removed leaving the placenta attached to the uterine wall. The fetuses were dried and maintained at $37^{\circ} \mathrm{C}$ (with heat lamps and warm moist gauze) and care was taken to apply minimal tension to the umbilical cord. Blood was obtained from axillary vessels within $10-15 \mathrm{~s}$ of cutting. The volume was sufficient for determining glucose and hormone concentrations for each fetus. Maternal blood was obtained simultaneously from tail veins so that maternal-fetal glucose ratios could be calculated. After blood sampling the fetus was killed by decapitation and the liver quickly removed and frozen in liquid nitrogen. Hepatic glycogen content and cytosolic PEPCK activity were measured for each fetus and pup. In some animals we did not sample blood but quickly froze the fetal liver as soon as the fetus was removed from the uterus. Hepatic glycogen concentrations and cytosolic PEPCK activities from these fetuses did not differ from those who underwent blood sampling before freezing the liver. We also determined DNA and protein content in brain and liver. We sampled from only the first two to three fetuses in a litter to avoid any potential effect of prolonged maternal anesthesia. Preliminary studies indicated that plasma glucose and insulin concentrations from these fetuses did not differ from values of fetuses in other positions in the uterus. A total of 20 to 25 litters comprised each group at each day of gestation.

Neonatal sampling. On day 21.5 , we delivered rat pups by cesarean section after stunning and cervical dislocation of the mother. As in previous studies, pups were quickly dried, separated from their placentas, and placed in chambers that provided humidified air at $37^{\circ} \mathrm{C}$. Pups had blood collected from severed axillary vessels and were then decapitated. We measured in sequential littermates plasma glucose, insulin, glucagon, and hepatic glycogen concentrations and PEPCK activity during the first $240 \mathrm{~min}$ of life. DNA and protein concentrations in brain and liver were obtained from other pups immediately at birth. Each group was comprised of 30 to 35 litters. Data at each time point for a group represent at least 30 pups.
Analyses. Plasma glucose concentrations were determined for each fetus and pup (Beckman II, Glucose Analyzer). Blood for hormone analysis was treated with Aprotinin (Trasylol 25:1 vol/ vol) and the plasma frozen at $-70^{\circ} \mathrm{C}$ until assay. We have reported the details of our analytical methods $(10,11)$. Both plasma insulin and glucagon concentrations were determined with double antibody radioimmunoassays with rat insulin (Novo Laboratories, Copenhagen, Denmark) and porcine glucagon (Eli Lilly, Indianapolis, IN) respectively as standards. Samples of 25$\mu \mathrm{l}$ were used for insulin and $50 \mu \mathrm{l}$ for glucagon determinations. For the insulin assay, the minimum detectable mass was 0.78 $\mu \mathrm{U} /$ assay tube and the coefficients of interassay and intraassay variation of rat plasma pool samples were 10.5 and $2.3 \%$. For glucagon, the minimum detectable mass was $7.7 \pm 2.0 \mathrm{pg}$ /assay tube, and coefficients of interassay and intraassay variation of rat plasma pool samples were 15.8 and $11.5 \%$, respectively. Hepatic cytosolic PEPCK activity and glycogen concentrations and tissue DNA and protein concentrations were determined as established in our laboratory. Mixed arteriovenous blood gas tensions and $\mathrm{pH}$ were determined with an ILC 1301 automated blood gas analyzer.

Fetuses and pups were dissected to obtain liver, kidneys, stomach and intestine, spleen, heart, carcass (muscle, skin, adipose tissue, and skeletal bones), and brain (cerebral hemispheres to midbrain). Organs and placentas were blotted dry and drained of as much blood as possible before weighing. Organs were also weighed after $12 \mathrm{~h}$ drying in an $40^{\circ} \mathrm{C}$ oven. Livers for biochemical measurements were quickly removed, weighed, cut into pieces, frozen in liquid nitrogen, and stored at $-70^{\circ} \mathrm{C}$.

Statistical analysis was performed using the Student's unpaired $t$ test for comparison of values between groups and paired $t$ tests for values within groups (12). Analyses were performed on a Cyber 170-780 computer at the Vogelback Computer Center of Northwestern University. Data are presented as the mean \pm SEM. This protocol was approved by the Animal Care Committee of Northwestern University Medical School.

\section{RESULTS}

General. In $7 \%$ of maternal rats in whom ligation was performed on day 14, fetuses were lost as a result of abortion, hemorrhage, or infection. In the remaining animals, ligation of every other artery on day 14 consistently resulted in a $50 \%$ reduction in litter size (from 8-14 to 4-7) and enhanced the growth of the remaining fetuses and placentas. We found no differences in litter restriction or growth effect between litters in which arteries were ligated to the uppermost or second highest fetus in a horn. The letter A designates the fetuses and pups who remained after selective ligation because they demonstrated accelerated growth after ablation of littermates. None of the A litters had spontaneous reabsorption of fetuses and three of 100 control litters had resorption of one fetus between days 14 and term.

The effect on fetal growth was less reproducible when ligation was performed on days other than day 14. When ligation was performed on days 11 to 13 , several rather than a single fetus were killed with each ligation and the growth of the surviving fetuses was not consistently increased. Thirty percent of mothers aborted. Ligation on days 15 to 20 never increased fetal growth. When more than $50 \%$ of secondary vessels were ligated on day 14 , there was a $60-70 \%$ loss rate in the fetuses whose arteries had not been ligated. The growth rate of the surviving fetuses was not greater than that of A fetuses in which $50 \%$ litter reduction had been performed. Albation of fewer than $50 \%$ of fetuses on any day of gestation caused inconsistent growth patterns in the remaining fetuses. Single artery ligation resulting in the death of one fetus had no effect upon the growth of the remaining fetuses.

Growth. Within $4 \mathrm{~h}$ of ligation on day 14 , fetuses whose uterine artery branches had been tied were dead. On days 16 and 17 , 
autolyzing fetal and placental tissue was still discernible within the amniotic membranes. By day 18 , only a small nubbin of coalesced tissue remained. Control and A fetuses and placentas were of similar weight from days 14 to 17 . From day 18 until birth, A fetuses and placentas were significantly heavier than controls. The rate of growth A fetuses was greater than that of controls $(1.50 \pm 0.15$ versus $1.00 \pm 0.14 \mathrm{~g} /$ day, $p<0.001)$ and was constant between days 18 and 21 (Fig. 2). At birth, A newborn pups weighed $5.84 \pm 0.05$ and controls, $5.20 \pm 0.05 \mathrm{~g}$ $(p<0.001)$. Placentas of A pups weighed $0.627 \pm 0.010 \mathrm{~g}$ and controls $0.526 \pm 0.010 \mathrm{~g}(p<0.001)$.

On days 14 to 17 , organ weight did not differ between $A$ and control fetuses. From day 18 onward, brain, liver, and carcass mass of A fetuses significantly exceeded control values (Fig. 3). Values for carcass mass of $\mathrm{A}$ fetuses on days 18 to 21.5 were $1.79 \pm 0.05,2.79 \pm 0.04,3.80 \pm 0.02,4.80 \pm 0.04$, and $5.00 \pm$ $0.05 \mathrm{~g}$. For control fetuses, values were $1.40 \pm 0.05,2.30 \pm 0.04$, $3.10 \pm 0.05,4.00 \pm 0.03$, and $4.40 \pm 0.04 \mathrm{~g}(p<0.01$ to 0.001$)$. The mass of heart, kidneys, spleen, and gastrointestinal tract did not differ between groups. Comparison of wet and dried tissue indicated that water comprised 75 to $80 \%$ of fetal body mass and did not differ between groups. From day 18 until term, DNA and protein concentrations in the brain and liver of $\mathrm{A}$ fetuses and pups were significantly increased compared to controls. Newborn A pups had brain DNA concentrations of $4.52 \pm 0.10$ $\mu \mathrm{g} / \mathrm{g}$ brain whereas control pups had $3.38 \pm 0.09 \mu \mathrm{g} / \mathrm{g}$ brain. Respective protein concentrations were $60.5 \pm 1.6$ and $52.8 \pm$ $1.0 \mathrm{mg} / \mathrm{g}$ brain. Hepatic DNA concentrations were $3.62 \pm 0.04$ $\mu \mathrm{g} / \mathrm{g}$ liver in A pups and $3.35 \pm 0.05 \mu \mathrm{g} / \mathrm{g}$ liver in control pups. Protein concentrations were $62.5 \pm 2.6 \mathrm{mg} / \mathrm{g}$ liver and $53.7 \pm$ $1.8 \mathrm{mg} / \mathrm{g}$ liver in A and control pups. All four sets of variables were significantly different between groups $(p<0.001$ level).

Litter number and fetal body mass were inversely related in $\mathrm{A}$ but not control groups. When linear regression analysis was used to relate mean newborn body mass to the number of pups in a litter for A animals, a significant association was apparent $(r=$ $0.789 n=151, p<0.001)$. In addition, to eliminate potential litter bias, we chose at random a single newborn from each litter and related its body mass to the number of pups in its litter. This too demonstrated a significant relationship (Fig. 4). Similar associations were apparent when a specific fetus (e.g. the second in the right horn of each litter) was related to litter number. The mean body mass of A pups in litters originally 12 to 14 reduced to six and seven was significantly greater than pups of control litters of $8(5.48 \pm 0.05$ versus $5.28 \pm 0.05, p<0.01)$. The relation between body mass and litter number was also significant when $\mathrm{A}$ and control litters were considered together although to a lesser degree than when A litters were considered alone. We could not identify any consistent pattern between a fetus' position in a uterine horn with body or placental mass.

Fetal metabolism. On days 18 and 19, A fetuses had significantly elevated plasma glucose and insulin and diminished glucagon concentrations compared to controls. On days 20 and 21 , fetal plasma glucose, insulin, and glucagon concentrations were equivalent in $\mathrm{A}$ and control fetuses. Maternal glucose concentrations did not differ between $A$ and control mothers at any point; thus fetal/maternal glucose ratios were significantly elevated in A fetuses on days 18 and 19 (Table 1). Hepatic PEPCK activity was low relative to neonatal values and did not differ between $\mathrm{A}$ and control fetuses from day 18 to term. Mean values ranged from 0.088 to $0.101 \mu \mathrm{mol}$ phosphoenolpyruvate $/ \mathrm{g}$ liver $/ \mathrm{min}$.

On days 18 and 19, A fetuses had significantly elevated hepatic glycogen concentrations. On days 20,21, and at birth, values did not differ between groups (Tables 1 and 2). On days 18 through 21 , arteriovenous $\mathrm{pH}$ and blood gas tensions did not differ between $\mathrm{A}$ and control fetuses (day 19: $\mathrm{A}, \mathrm{pH} 7.23 \pm 0.008 ; \mathrm{PCO}_{2}$ $62 \pm 4$ torr; $\mathrm{PO}_{2} 25 \pm 4$ torr; control, $\mathrm{pH} 7.20 \pm 0.008 ; \mathrm{PCO}_{2} 61$ \pm 5 torr; $\mathrm{PO}_{2} 25 \pm 5$ torr).

Neonatal metabolism. At birth, A pups had plasma glucose concentrations similar to controls; however, at 20 and $60 \mathrm{~min}$, A pups had significantly diminished glucose concentrations. Values were similar to those of controls at $120 \mathrm{~min}$ and remained so at $240 \mathrm{~min}$ (Fig. 5). At 20 and $60 \mathrm{~min}$ A pups had significantly increased plasma insulin concentrations; at birth and after 60

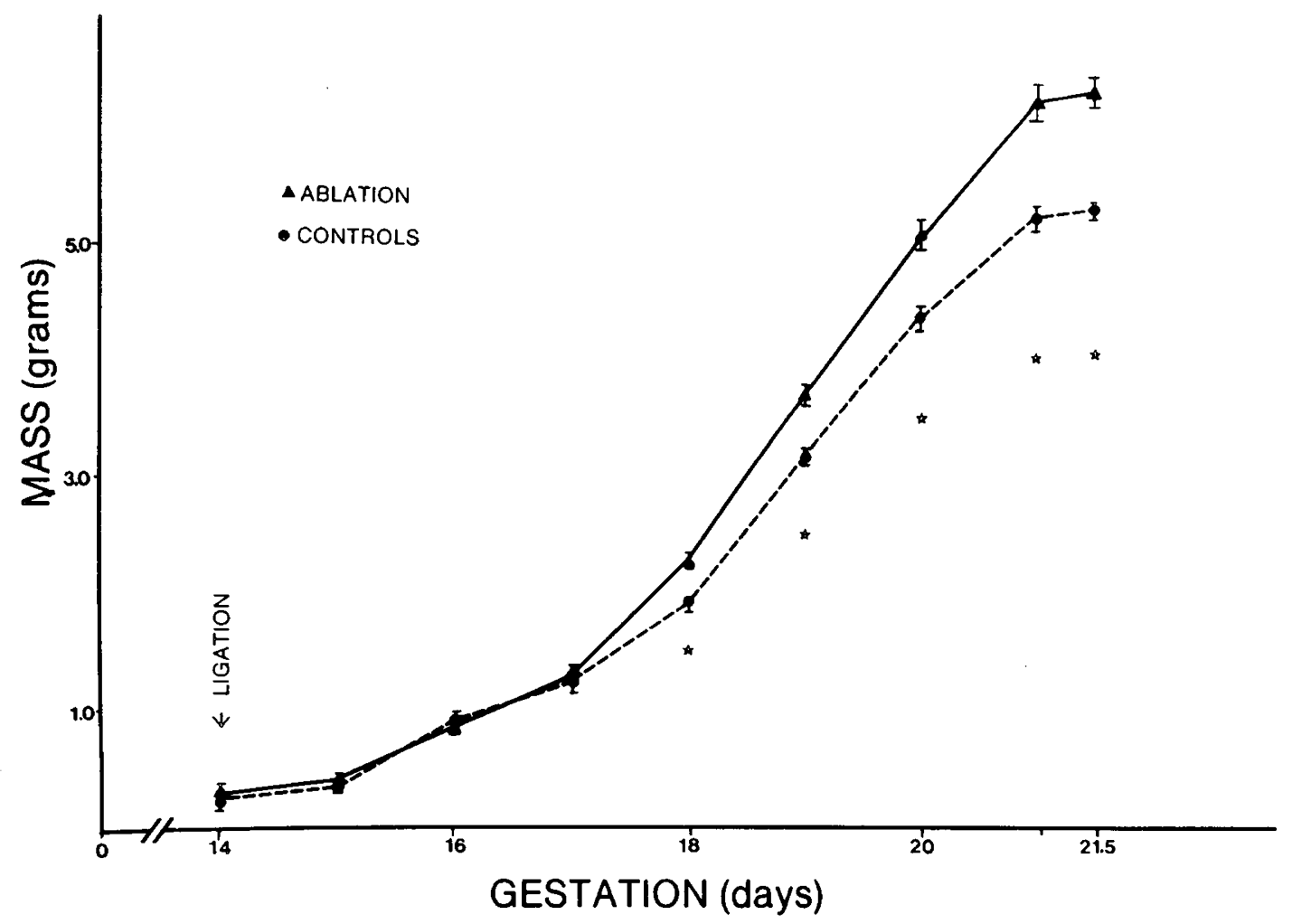

Fig. 2. Body mass of surviving fetuses in A and control litters relative to gestation. Four days after ligation fetuses of A litters significantly outweighed controls $(p<0.001)$. This difference persisted until birth. 
min values were similar to controls (Fig. 5). Plasma glucagon concentrations did not differ between $\mathrm{A}$ and control groups at any point.

Hepatic glycogen concentrations were significantly elevated in A compared to controls at 20 and $60 \mathrm{~min}$. At birth, 120, and $240 \mathrm{~min}$, A glycogen concentrations were similar to controls (Table 3). In control pups, hepatic cytosolic PEPCK activity at 120 and $240 \mathrm{~min}$ was significantly increased compared to earlier

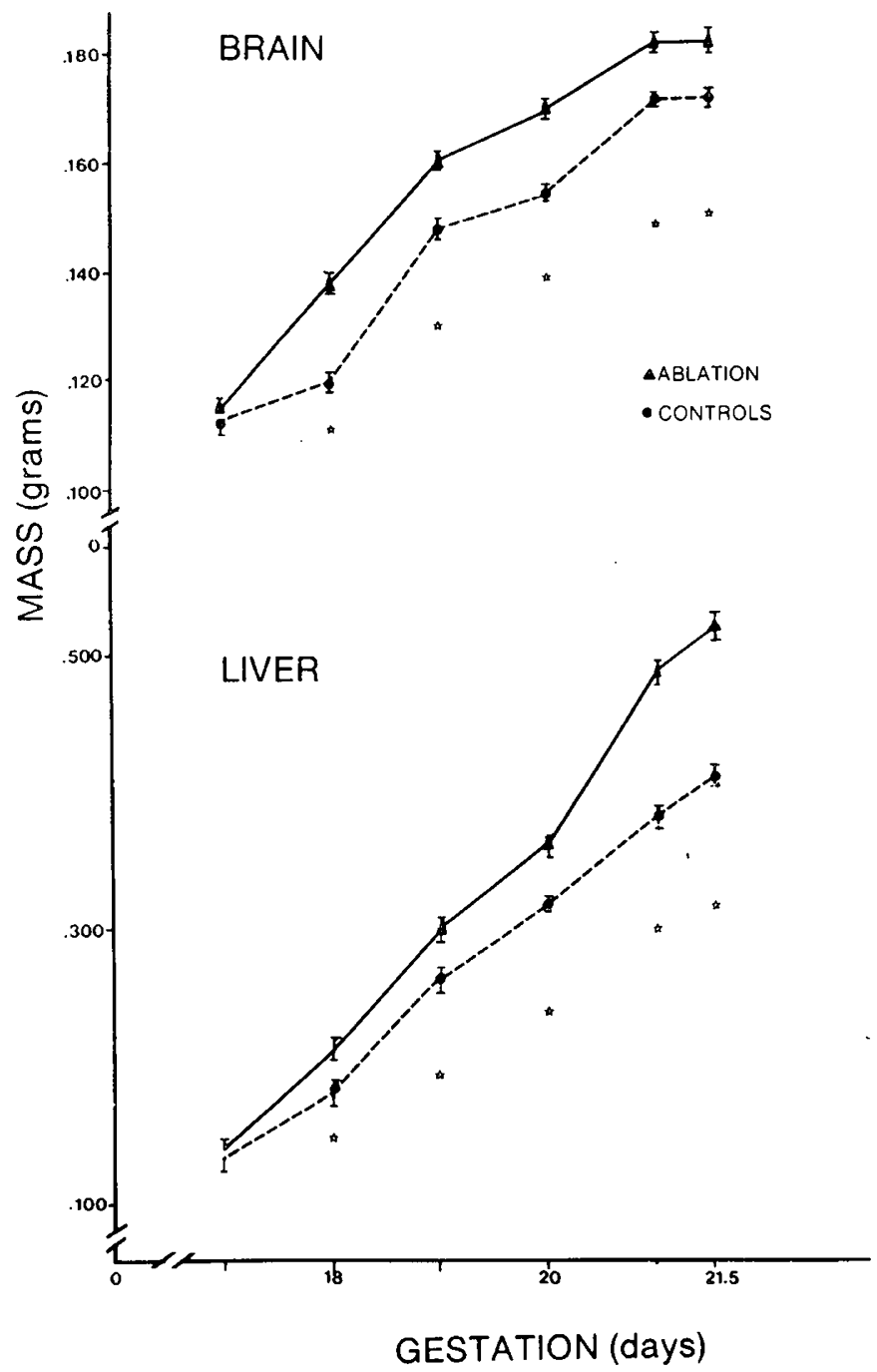

Fig. 3. Growth of fetal brain and liver in A and control litters. From day 18 to birth, fetuses of A litters had significantly increased brain and liver mass $(p<0.001)$ values. Values for control pups at 120 and 240 min significantly exceeded those of A pups (Table 2).

\section{DISCUSSION}

Reducing litter number in each uterine horn by approximately $50 \%$ during the latter third of gestation accelerates the growth of the remaining fetuses. Although our study did not identify all of

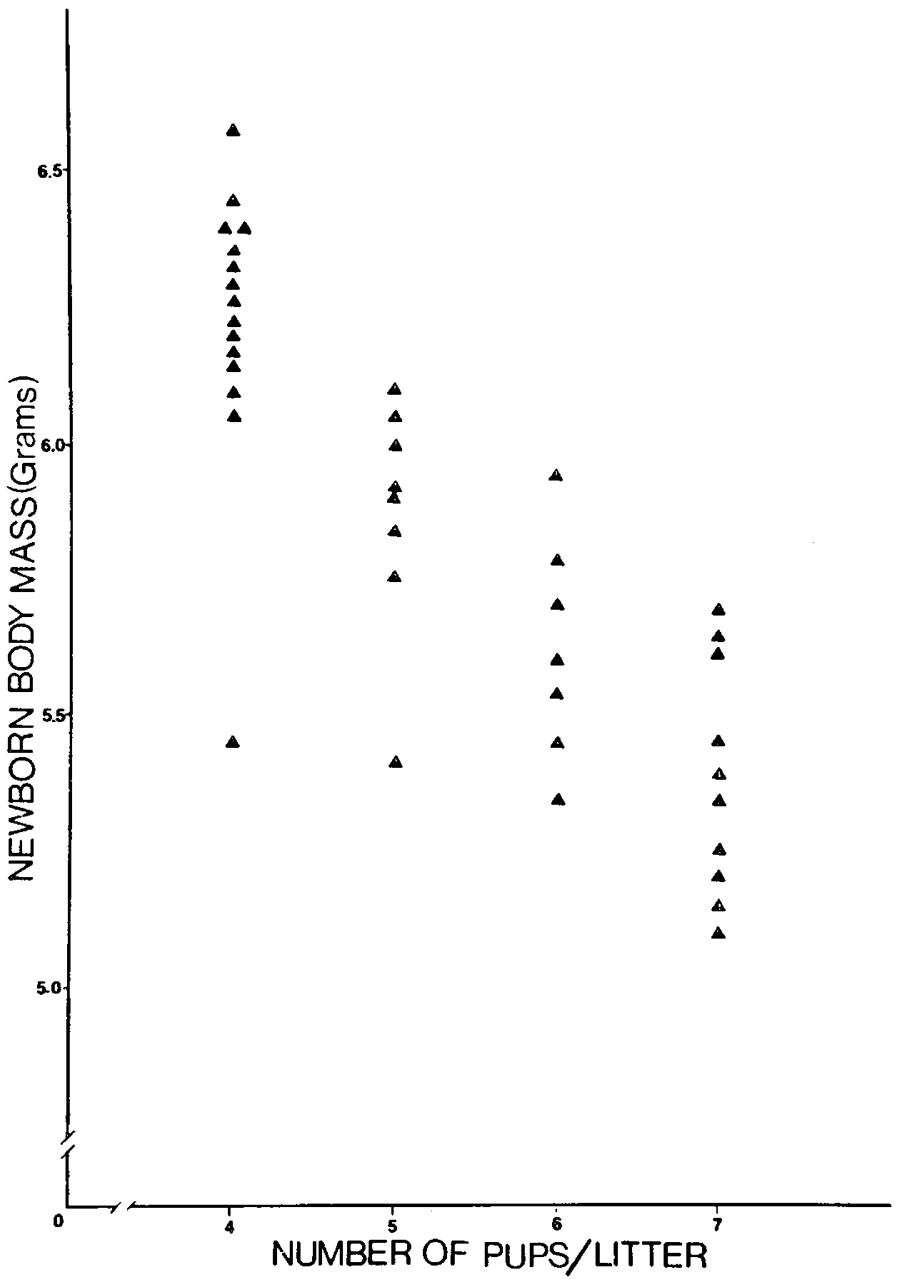

Fig. 4. Newborn body mass versus number of pups in A litters. We randomly selected a pup from each litter by assigning a number to each pup of a litter and using a random number table to select one. This pup's newborn body mass was significantly related to the number of pups in its litter $(r=-0.823, n=40, p<0.001)$.

Table 1. Metabolic variables in fetal rats

\begin{tabular}{|c|c|c|c|c|c|c|c|c|c|c|}
\hline & \multicolumn{10}{|c|}{ Gestation (days) } \\
\hline & \multicolumn{3}{|c|}{18} & \multicolumn{3}{|c|}{19} & \multicolumn{2}{|c|}{20} & \multicolumn{2}{|c|}{21} \\
\hline & Ablated & & Control & Ablated & & Control & Ablated & Control & Ablated & Control \\
\hline Glucose $(\mathrm{mg} / \mathrm{dl})$ & $59.3 \pm 4.0$ & $*$ & $41.0 \pm 3.0$ & $65.4 \pm 3.6$ & $*$ & $53.1 \pm 4.4$ & $70.4 \pm 5.8$ & $68.0 \pm 6.1$ & $75.1 \pm 4.0$ & $74.1 \pm 5.2$ \\
\hline Fetal/maternal glucose & $0.68 \pm 0.05$ & $*$ & $0.49 \pm 0.06$ & $0.70 \pm 0.08$ & $*$ & $0.57 \pm 0.04$ & $0.77 \pm 0.07$ & $0.75 \pm 0.06$ & $0.81 \pm 0.07$ & $0.84 \pm 0.08$ \\
\hline Insulin $(\mu \mathrm{U} / \mathrm{ml})$ & $148.0 \pm 10.1$ & $*$ & $105.1 \pm 10.3$ & $175.6 \pm 18.1$ & $*$ & $144.3 \pm 13.0$ & $160.1 \pm 13.1$ & $150.1 \pm 11.1$ & $148.1 \pm 13.3$ & $140.1 \pm 12.1$ \\
\hline Glucagon $(\mathrm{pg} / \mathrm{ml})$ & $150.1 \pm 15.1$ & $*$ & $203.3 \pm 20.1$ & $108.1 \pm 20.1$ & $*$ & $195.6 \pm 20.7$ & $300.1 \pm 35.1$ & $280.6 \pm 31.1$ & $400.3 \pm 33.1$ & $407.8 \pm 35.1$ \\
\hline Glycogen (mg/g liver) & $25.7 \pm 1.0$ & $*$ & $14.8 \pm 1.0$ & $49.8 \pm 5.1$ & $*$ & $36.2 \pm 3.9$ & $51.4 \pm 2.0$ & $49.2 \pm 4.2$ & $70.3 \pm 3.2$ & $70.1 \pm 3.0$ \\
\hline
\end{tabular}

\footnotetext{
* Differences between groups on specified day of gestation, $p<0.01$ to 0.001 .
} 
Table 2. Hepatic glycogen content and cytosolic PEPCK activity in newborn rats

\begin{tabular}{|c|c|c|c|c|c|c|c|c|c|c|c|c|c|c|}
\hline & \multicolumn{14}{|c|}{ Age (min) } \\
\hline & \multicolumn{2}{|c|}{0} & \multicolumn{3}{|c|}{20} & \multicolumn{3}{|c|}{60} & \multicolumn{3}{|c|}{120} & \multicolumn{3}{|c|}{240} \\
\hline & A & Control & A & & Control & A & & Control & $\mathrm{A}$ & & Control & A & & Control \\
\hline \multirow[t]{3}{*}{ Glycogen (mg/g liver) } & 71.4 & 72.1 & 63.8 & $*$ & 53.2 & 51.0 & $*$ & 41.3 & 35.6 & & 31.9 & 33.0 & & 32.3 \\
\hline & \pm & \pm & \pm & & \pm & + & & \pm & \pm & & \pm & \pm & & \pm \\
\hline & 3.2 & 6.4 & 3.1 & & 3.1 & 3.3 & & 2.8 & 4.0 & & 4.9 & 3.5 & & 2.0 \\
\hline \multirow{3}{*}{$\begin{array}{l}\mathrm{PEPCK}(\mu \mathrm{mol} \mathrm{PEP} / \mathrm{g} \\
\text { liver } / \mathrm{min})\end{array}$} & 0.101 & 0.121 & & & & 0.120 & & 0.130 & 0.125 & $*$ & 0.201 & 0.129 & $*$ & 0.390 \\
\hline & \pm & \pm & & & & \pm & & \pm & \pm & & \pm & \pm & & \pm \\
\hline & 0.008 & 0.022 & & & & 0.011 & & 0.018 & 0.019 & & 0.019 & 0.020 & & 0.035 \\
\hline
\end{tabular}

${ }^{*}$ Differences between groups at specified time, $p<0.01$ to 0.001 .
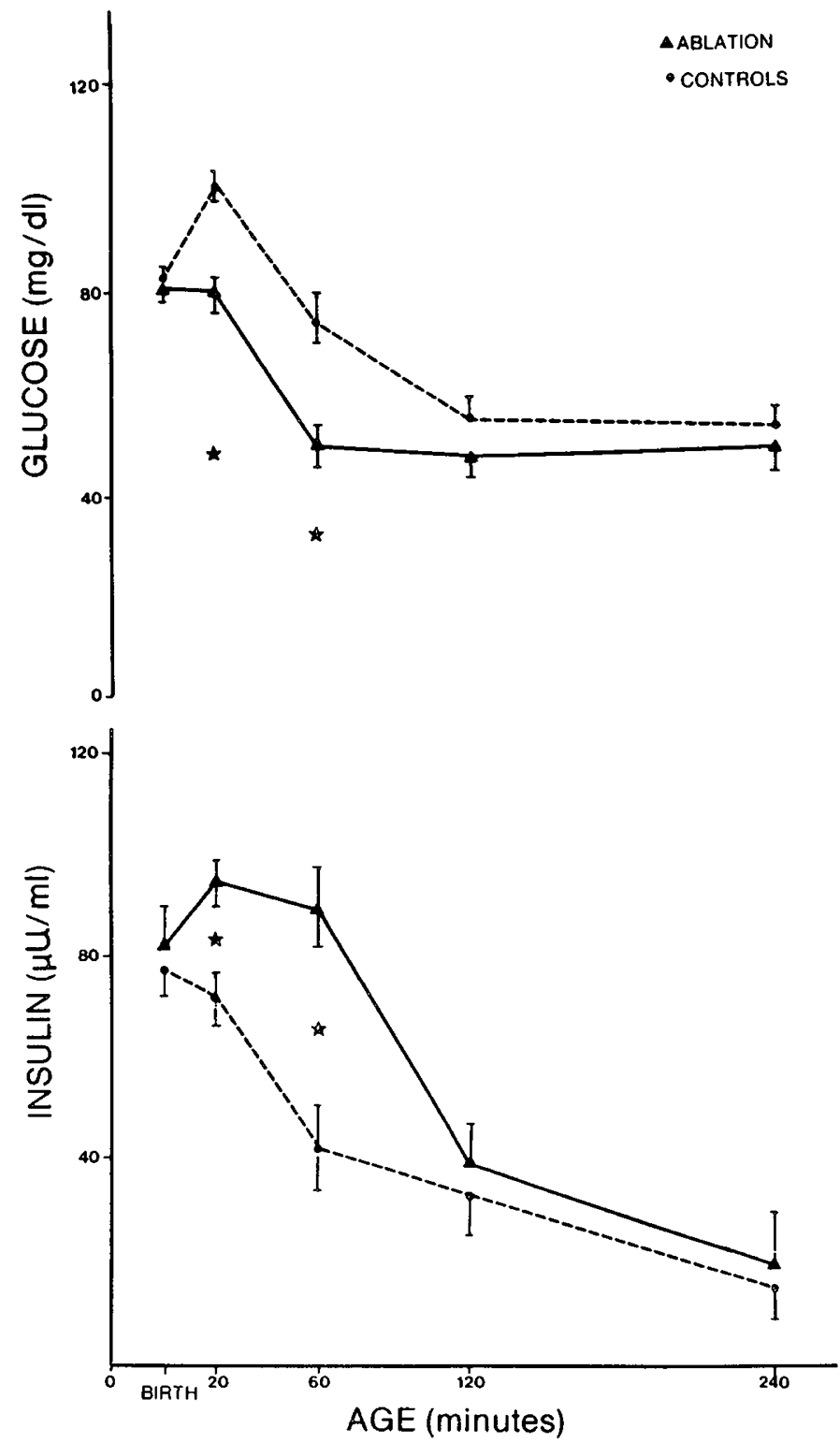

Fig. 5. Plasma glucose and insulin concentrations in $A$ and control rat pups. A pups had significantly diminished plasma glucose $(p<0.001)$ and elevated insulin $(p<0.01)$ concentrations at 20 and $60 \mathrm{~min}$ of life.

the factors responsible for this, it does suggest that selective artery ligation may increase glucose provision to surviving fetuses with subsequent stimulation of insulin secretion. A surprising finding was the development of hyperinsulinemia associated with hypoglycemia in newborn pups of ablated litters.
Under normal circumstances, the relation between litter size and fetal growth is limited. A roughly significant negative correlation exists between body weight and naturally occurring litter number in the rat when litters ranging from two to 17 fetuses are considered (3). When the upper and lower extremes of litter size are excluded, this relation is no longer demonstrable $(3,13)$. It is thus not surprising that these variables were not significantly related in our control litters of eight to 14 fetuses.

However, artificial restriction of litter size not only enhances the growth of the remaining fetuses but results in a strongly significant negative correlation between fetal number and body growth. The mean birth weight of the term pups of our A litters not only significantly exceeded that of controls but was also considerably greater than that reported for fetuses of naturally occurring litters $(3,13,14)$. The enhancing effect of $A$ on fetal growth is also confirmed by the observation that the mean weight of pups in litters orignally 12 to 14 reduced to six and seven significantly exceeded that of control pups with naturally occurring litters of eight.

As reported in other models of accelerated intrauterine growth $(5,6)$, the A fetuses had significantly heavier placentas than controls. That is consistent with the general observation that fetal and placental growth parallel one another. We speculate that the increased placental mass may have resulted from enhanced blood flow to the placenta as a result of vessel ligation. It probably also represents the increased functional state of the placenta under these conditions.

Studies in the guinea pig (15), rabbit (16), and rat (17) have demonstrated a relation between uteroplacental blood flow and fetal growth. Uteroplacental blood flow directly influences metabolic fuel provision and gaseous exchange to the fetus (18). Inasmuch as we did not measure uteroplacental blood flow, we can only speculate if selective artery ligation increased blood flow to the remaining fetuses. Arteriovenous blood gas tensions and $\mathrm{pH}$ did not differ between $\mathrm{A}$ and control fetuses. This does not negate the possibility of increased blood flow in A litters because the partial pressure of gases and $\mathrm{pH}$ should not necessarily increase with greater than normal blood flow. However, the increased plasma glucose concentrations and fetal/maternal glucose ratios in the surviving fetuses of A litters suggest that blood flow and glucose provision were enhanced to these fetuses. The increased plasma insulin and hepatic glycogen concentrations and diminished glucagon concentrations also indicate that increased glucose provision to the fetus rather than stimulated endogenous fetal glucose production was responsible for the increase in fetal plasma glucose concentrations. On days 18 and 19 , glucose was available in sufficient quantity not only to enhance growth but also to increase hepatic glycogen deposition significantly. The fact that hepatic glycogen and insulin concentrations were not increased on days 20,21 , and at birth suggests that maternal glucose provision was decreased compared to days 18 and 19; however, the amount of glucose provided was sufficient to sustain an increased rate of body growth. In this regard, Fletcher et al. (19) reported that rabbit fetuses whose growth had 
been increased by reduction of litter size had increased insulin concentrations on day 30 of the rabbit's 32-day gestation. Our data, as theirs, indicate a link between alterations in litter size, a physical variable responsible for fetal growth, with changes in fetal metabolism.

Insulin is an important stimulator of fetal growth. Fetal hyperinsulinemia accelerates the growth of adipose, hepatic, muscle, and connective tissues $(1,2)$. The increased glucose availability in A fetuses stimulated insulin secretion, thereby enhancing the growth of liver and carcass. This insulin effect is confirmed by the increased hepatic glycogen concentrations on these days. The increased protein and DNA concentrations in livers of A fetuses suggest that the increased growth of this organ resulted from both cellular hypertrophy and hyperplasia. Inasmuch as we were unable to obtain adequate fetal plasma samples from day 15 to 17 , it is unclear if glucose and insulin concentrations were increased before day 18 . The observations that fetal $\beta$-cell secretion of insulin is sluggish in response to secretogogue stimulation (20) and that plasma insulin was already elevated in A fetuses on day 18 suggest that provision of plasma glucose and perhaps other metabolic fuels might have already been increased before this time.

Although these observations indicate an important role for increased glucose and insulin availability in stimulating the growth of A fetuses, other unidentified factors were probably also important. On days 20 and 21 , fetal plasma glucose and insulin availability had returned to control levels in A fetuses. This resulted in hepatic glycogen concentrations in the normal range. Despite this, the body mass of A fetuses continued to be significantly greater than controls and their rate of growth was similar to that between days 18 and 19 . Also, from days 18 to birth, brain growth was significantly increased in A fetuses. Whereas it has been demonstrated that the rat brain has insulin receptors (21), and insulin administered in the physiologic range stimulates the synthesis of specific macromolecules and RNA (22), no studies have demonstrated that insulin stimulates actual brain growth. The A fetuses and pups had increased brain DNA and protein concentrations suggesting that litter reduction in some unknown manner stimulates both brain hyperplasia and hypertrophy. This phenomenon has been reported in other models of fetal $\mathrm{A}(5,6,23,24)$. These observations indicate that growthpromoting factors other than insulin were operating in A fetuses.

Several methods for accelerating fetal growth by reducing litter size have been described. Ligation of one uterine horn in the rat before conception (23), needle aspiration of fetuses in rabbits (5), and crushing (25) or electrocautery (6) of fetuses have all been reported to accelerate the growth of surviving fetuses. The studies reporting these techniques used limited numbers of animals and did not control for the potential effect of litter number on fetal growth. Inasmuch as the reproducibility of these techniques was not reported, it is difficult to assess their potential usefulness. Because of these concerns, we matched each experimental litter to a control having the same number of fetuses. A very few of these had a fetal resorption. The $93 \%$ success rate indicates that selective vessel ligation on day 14 is quite reproducible. Our experience concurs with that of others indicating that when fewer than $50 \%$ of fetuses in the rat are killed, the growth of the surviving fetuses is less likely to be enhanced. Although reducing litter size more than $50 \%$ is associated with accelerated growth, this also increases fetal loss. For these reasons, we believe that litter reduction by $50 \%$ on day 14 is a good method to accelerate growth.

Although control pups demonstrated the expected increase in plasma glucose concentration at $20 \mathrm{~min}$ of neonatal life, A pups had significantly diminished values at this and $60 \mathrm{~min}$. This hypoglycemia resulted in part from elevated plasma insulin concentrations that limited hepatic glycogen mobilization. Glucagon secretion did not increase possibly as a result of the transient nature of the hypoglycemia and the sluggish response of the neonatal alpha cell to glucose (26). In the rat and other species, glucagon stimulates while insulin delays the induction of hepatic cytosolic PEPCK, a critical gluconeogenic enzyme in the newborn rat (27). The normal increase in glucagon and decrease in insulin in the newborn rat are important to induce this enzyme and facilitate glucose production $(27,28)$. The elevations of insulin and lack of increase of glucagon in hypoglycemic A newborns may have delayed PEPCK induction thereby contributing to hypoglycemia in A newborns.

The significant elevations of plasma insulin in A newborn pups is particularly difficult to explain because insulin concentrations in A fetuses were normal during the last days of gestation. This phenomenon of neonatal hypoglycemia associated with increased body size is similar to the unexplained increased incidence of hypoglycemia that occurs in large for gestational age human neonates who are not infants of diabetic mothers $(7,29)$. Neonatal hypoglycemia has also been observed in another model of accelerated fetal growth in the rat. Insulin injection in the rat fetus during late gestation stimulates fetal growth and also results in neonatal hypoglycemia as a consequence of hyperinsulinemia $(30,31)$. Such rats at 10 to 12 wk demonstrate delayed glucose clearance in response to glucose challenge (32). The mechanisms for altered glucose homeostasis in these conditions remain to be delineated.

Ablation of fetuses with a $50 \%$ reduction in litter number will be useful for identifying and further characterizing the mechanisms responsible for accelerated intrauterine growth. It may also determine the causes of the hypoglycemia that often accompanies macrosomia in the neonatal period.

\section{REFERENCES}

1. Freinkel N 1980 Of pregnancy and progeny. Diabetes 29:1023-1035

2. Hill DJ, Milner RDG 1985 Insulin as a growth factor. Pediatr Res 19:879-886

3. Barr M, Jensch R, Brent R 1970 Prenatal growth in the albino rat: effects of number, intrauterine position, and resorptions. Am J Anat 128:413-428

4. McLaren A, Michie D 1960 Control of prenatal growth in mammals. Nature 187:363-365

5. van Marthens E, Grauel L, Zamenhof S 1972 Enhancement of prenatal development by operative restriction of litter size in the rabbit. Life Sci 11:1031-1035

6. van Marthens E, Grauel L, Zamenhof S 1975 Enhancement of prenatal development in the rat by operative restriction of litter size. Biol Neonate 25:53-56

7. Lubchenko LO, Searls DT, Brazie JW 1972 Neonatal mortality rate: relationship to birth weight and gestational age. J Pediatr 81:814-820

8. Lubchenko LO, Bard H 1971 Incidence of hypoglycemia in newborn infants classified by birth weight and gestational age. Pediatrics 47:831-838

9. Girard JR, Ferre P, Gilbert M, Kervran A, Assan R, Marks EB 1977 Fetal metabolic response to maternal fasting in the rat. Am J Physiol 232:E456462

10. Bussey M, Finley S, LaBarbera A, Ogata ES 1985 Hypoglycemia in the newborn growth retarded rat. Delayed phosphoenolpyruvate carboxykinase induction despite increased glucagon availability. Pediatr Res 19:363-367

11. Ogata ES, Paul RI, Finley S, 1987 Limited maternal fuel availability due to hyperinsulinemia retards fetal growth and development in the rat. Pediatr Res 22:432-437

12. Snedecor GW, Cochran WG 1972 Statistical Methods. Iowa University Press, Ames, IA

13. Norman W, Bruce N 1979 Fetal and placental weight relationships in the albino rat near term. Teratology 19:245-250

14. Wigglesworth JS 1964 Experimental growth retardation in the fetal rat. J Pathol Bacteriol 88:1-13

15. Peeters LLH, Sparks JW, Grutters G, Girard J, Battaglia FC 1982 Uteroplacental blood flow during pregnancy in the chronically catheterized guinea pig. Pediatr Res 16:716-720

16. Leduc B 1972 Maternal placental blood flow and gestational age in rabbits. Am J Obstet Gynecol 122:374-378

17. Gilbert M, Leturque A 1982 Fetal weight and its relationship to placental blood flow and placental weight in experimental intrauterine growth retardation in the rat. J Dev Physiol 4:237-246

18. Peeters L, Martensson L, vanKreel B, Saxena P, Wallenburg H 1986 Movement of oxygen, glucose, and lactate across the uterus of the awake near-term guinea pig. Pediatr Res 20:730-734

19. Fletcher JM, Falconer J, Bassett JM 1982 The relationship of body and placental weight to plasma levels of insulin and other hormones during development in fetal rabbits. Diabetologia 23:124-130

20. Girard JR, Kervran A, Soufflet E, Assan R 1974 Factors affecting the secretion of insulin and glucagon by the rat fetus. Diabetes 23:310-316

21. Clarke D, Boyd FT, Kappy MS, Raizada MK 1984 Insulin binds to specific receptors and stimulates 2 -deoxyglucose uptake in cultured glial cells from 
rat brain. J Biol Chem 259:11672-11675

22. Clark D, Boyd FT, Kappy MS, Raizada, MK 1985 Insulin stimulates macromolecular synthesis in cultured glial cells from rat brain. Am $\mathbf{J}$ Physiol 249:C484-489

23. van Marthens E, Zamenhof S 1969 Deoxyribonucleic acid content of neonatal rat cerebrum increased by operative restriction of litter size, Exp Neurol 23:214-219

24. Zamenhof S, Grauel L, van Marthens E 1971 Study of possible correlations between perinatal brain development and placental weight. Biol Neonate 18:140-145

25. Croskerry PG, Smith GK, Hall S, Shepard B 1978 Fetal and placental growth in the rat following differential reduction of litter size. Biol Neonate 33:3138

26. Girard JR, Cuendet GS, Marliss EB, Kervran A, Rieutort M, Assan R 1973 Fuels, hormones, and liver metabolism at term and during the early postnatal period in the rat. $\mathrm{J}$ Clin Invest 52:3190-3200

27. Girard JR, Caquet D, Bal D, Fuillet I 1973 Control of rat liver phosphorylase, glucose 6 phosphatase, and phosphoenolpyruvate carboxykinase activities by insulin and glucagon during the perinatal period. Enzyme 15:272-285

28. Beale E, Andreone T, Koch S, Granner M, Granner D 1984 Insulin and glucagon regulate cytosolic phosphoenolpyruvate carboxykinase (GTP) mRNA in rat liver. Diabetes 33:328-332

29. Kliegman R, Gross $T$, Morton $S$, Dunnington $R$. Intrauterine growth and postnatal fasting metabolism in infants of obese mothers. J Pediatr 104:601607

30. Catlin E, Cha CM, Oh W 1985 Postnatal growth and fatty acid synthesis in overgrown rat pups induced by fetal hyperinsulinemia. Metabolism 34:11101114

31. Ogata ES, Collins JW, Finley S 1988 Insulin injection in the fetal rat. Accelerated intrauterine growth and altered fetal and neonatal glucose homeostasis. Metabolism 37:649-655

32. Cha CM, Gelardi N, Oh W 1987 Accelerated growth and abnormal glucose tolerance in young rats exposed to fetal hyperinsulinemia. Pediatr Res $21: 83-$ 87 